\title{
Function Design of Firefighting Personal Protective Equipment: A Systematic Review
}

\author{
Md Mayedul Islam and Yingying Wu* \\ Department of Interior Design and Fashion Studies, Kansas State University, USA
}

*Corresponding author: Yingying Wu, Department of Interior Design and Fashion Studies, Kansas State University, 320 Justin Hall, 1324 Lovers Lane, Manhattan, Kansas, 66503, USA.

Received Date: September 14, 2020

Published Date: September 25, 2020

\begin{abstract}
Firefighting is a hazardous occupation. It has a variety of risks associated with fatal and non-fatal injuries. To protect against heat and unsafe environment, firefighters wear personal protective equipment (PPE), including self-contained breathing apparatus (SCBA), boots, helmet, and thermal protective clothing, including coat, pants, hood, and gloves. To obtain knowledge of injuries and issues related to the functional design of firefighting PPE, especially firefighting PPE for female firefighters, a systematic review of related literature in related disciplines was conducted. It was found heavy and bulky turnout ensemble and inappropriate sizing system are the two dominant barriers to effective and efficient firefighting performance. Also, research on female firefighters' PPE is limited but highly demanded. Therefore, this review provides insights for improving the design, fit, and functionality of future PPE. In particular, it summarizes the design and sizing issues of existing PPE products, thus providing a valuable guide to the industry in improving future functional design and production of PPE. It also identifies critical knowledge gaps of firefighting PPE and specified future research opportunities, such as improving the design of firefighter PPE based on gender, height, age, and the category of firefighters.
\end{abstract}

Keywords: Firefighting; Personal protective equipment; Female firefighters; Functional design; Injuries; Safety; Performance

Abbreviations: PPE: Personal Protective Equipment; SCBA: Self-Contained Breathing Apparatus; NFPA: National Fire Protection Association; FEMA: Federal Emergency Management Agency

\section{Introduction}

In recent years, multiple countries and regions worldwide, such as Australia and California, have experienced the deadliest and most destructive wildfire in their history. For instance, according to the California Department of Forestry and Fire Protection, there were 5,924 fires reported and 1,059,583 acres were burned in California from January 1, 2020 through August 20, 2020 [1]. Those devastating fires drew a significant amount of attention to the protection and safety issues of firefighters.

Firefighting is an occupation with societal and moral importance, but hazardous [2]. Firefighters save not only physical property and environment but also people's lives and well-being [3]. Their duties range from responding to fire ground emergencies, including structures fires, vehicle fires, brush fires, to a non-fire emergency such as rescue calls, hazardous calls, and natural disaster as the first responders in a community [4-6]. However, to perform those duties, firefighters expose themselves to substantial physical risks and psychological stress. They deal with life-threatening situations such as dangerous fire suppression scenarios, motor vehicle accidents, chemical hazards, burned bodies, and suicides. Additionally, they experience extreme psychological stress, particularly in failed rescue efforts, including knowing the victim and witnessing the death of a coworker [6,7]. Furthermore, firefighters' strenuous work may continue to a period of unpredictable duration under conditions of high environmental heat strain [8-11]. 
To enhance safety and improve performance, firefighters are expected to constantly enhance their physical body strength and wear advanced firefighting gear on duty. For example, they train on a regular basis to perform tasks that demand high muscular performance and motor coordination, such as the clearing of debris with heavy manual tools and roof work.

According to the 2015 United States Fire Department Profile, there were 29,727 fire departments domestically in 2015, which had 1,160,450 firefighters in total. Seventy percent of them were volunteer firefighters, and the rest of them were career firefighters [10]. On the other hand, half of the firefighters are forty or more than forty years old, and there were about 2170 female firefighters [10]. However, an increasing number of female firefighters have been choosing this occupation [12].

\section{Personal Protective Equipment (PPE)}

To protect against heat and hazardous environments, firefighters wear personal protective equipment (PPE), which includes a helmet, boots, thermal protective clothing (coat, pants, hood, gloves), and a self-contained breathing apparatus (SCBA) [13]. The design and production of PPE is regulated by the National Fire Protection Association (NFPA) 1971 and 1981 standards. NFPA has standard methods for rigorous testing of firefighting equipment. The purpose of these tests is to protect firefighters from flame and high heat and exposure to hazardous liquid, physical, and electrical hazards [14].

The PPE is necessary for the health, safety, and performance of the firefighting tasks. However, firefighters, particularly female firefighters, frequently reported dissatisfaction with their turnout gears $[12,15,16]$. For example, previous studies show that the heavyweight and bulkiness of PPEs increase the risks of injuries of the firefighters and limit firefighters' performance because it results in barriers to mobility and comfort $[13,17,18]$.

\section{Research objectives}

The purpose of this study is to systematically review published literature related to 1) firefighters' duty associated injuries, risks, and issues in hazardous environment of firefighting, and 2) the current advancement in the functional design aspect of firefighters' PPE, particularly concerns related to female firefighters' PPE. Another goal of this review paper is to identify research gaps and provide recommendations for positioning new research activities.

\section{Method}

To achieve the objectives mentioned above, a systematic review, which is "a means of identifying, evaluating and interpreting all available research relevant to a particular research question, or topic area, or phenomenon of interest" was conducted [19]. The review process started with three keywords: firefighter, female firefighter, and personal protective equipment. These keywords were arranged in multiple combinations by using Boolean AND's to get sophisticated search strings.
Using the search strings mentioned above, related literature was extracted from Web of Science database, which has comprehensive peer-reviewed academic literature coverage. Primarily, 1164 literature published were found without a filter of time in the Web of Science database. The articles that did not address firefighting PPE and repetitive items extracted from more than one search strings were removed from the review list. Based on the title's relevance with the topic, then 111 literature were identified for abstract screening. Meanwhile, the researchers completed a batch of hand searches using Google Scholar to collect additional literature based on multiple publications' reference lists to ensure comprehensive coverage of related topics. Finally, forty-nine articles and eight other types of literature such as reports were identified for a thorough review.

\section{Results}

\section{Analysis of publications distributed in various journals}

In total, thirty-three journals published research on firefighters' protective equipment and the injuries related to firefighters' protective gear. Ergonomics published the highest number of papers (four). National Fire Protection Association, one of the leading sources of information and knowledge regarding fire, electrical, and related hazards, also published four papers on related topics [20]. However, twenty-three journals only published one article. Meanwhile, according to the articles' publication year extracted from both the electronic database and hand search, most of the articles were published after the year 2010. No relevant article was found before 1990 in the Web of Science database, although the search was not filtered by time.

\section{Articles focusing on female firefighters}

Very few articles focused primarily on female firefighters. Only nine out of the fifty-seven reviewed publications were centering on female firefighters (Table 1). Varies issues of female firefighters' PPE were reported. It was particularly reported that it was more challenging for female firefighters than for male firefighters to find satisfying PPE and female firefighters tended to customize and/or alter their PPE $[12,15]$.

\section{Discussion}

\section{Injuries}

According to a report on firefighter injuries issued by the NFPA (2016), approximately 62,085 firefighters were injured on duty in 2016. Among them, $39.2 \%$ of the injuries occurred during the fire ground operations [21]. The top three causes of fire ground injuries were identified as (a) overexertion or strain (27.1\%), (b) falls, jumps, or slips (21.0\%), and (c) exposure to fire products $(13.6 \%)[21,22]$. On the other hand, for several years, the NFPA has reported the sudden cardiac death as the number one cause of inline duty deaths of the firefighter [23]. According to NFPA, in 2017, of the total deaths while on duty, sudden cardiac death (29 deaths) accounted for most deaths [24]. 
Injuries related to firefighting PPE: Firefighting PPE is critical to firefighters as it protects against heat stress, hazardous chemicals, gas, and physical collision [25]. Firefighters consider PPE's safety/ protection, mobility, and comfort as the three most important factors when evaluating their gear [15]. To provide adequate and appropriate protections, as well as to satisfy firefighters' physical and psychological needs, the size and fit, fabrication, and design of a turnout ensemble should be well developed in a holistic manner.

According to an estimation between November 2005 and December 2009, there were four main reasons for firefighters' work-related burn injuries: improper removal or dislodging of equipment, failure of equipment to protect the firefighter (either because of equipment misuse or design flaws), training errors, and burns from sweat evaporation. A study found that faulty equipment design and misuse often (70\%) resulted in steam or hot fluids entering the firefighters' turnout gear in vulnerable areas of firefighters [26]. Various studies also identified that weak areas usually are interfaces where two pieces of equipment overlapped or failed to overlap [26,27]. The integrity of protection in these interfaces is a significant issue for improving mobility, comfort, and safety. For instance, poorly-fitted pants frequently ride up above the boots, particularly when in a crawl position, exposing the calf to heat hazards [27]. Besides, the reasons why firefighters sometimes chose to work without PPE were also reported: (1) firefighters felt PPE interfering with physical performance, (2) firefighters felt donning gear might slow down a rescue, (3) firefighters were lack of knowledge relevant to PPE, and (4) some cultural factors unique to the profession [28,29].

Injuries related to the bulkiness and inflexibility of PPE: The bulkiness and inflexibility of PPE are the dominant factors of a significant number of injuries. They can limit firefighters' mobility while performing firefighting tasks such as climbing ladders, dragging hoses, and entering/exiting emergency vehicles [25,30] First, the massive weight of firefighting PPE (approximately 55lb or $22.1 \mathrm{~kg}$ in total) intensifies firefighters' fatigue with increased energy expenditure [17,31-33], causing stressful situation by long working hours and persistent sleep disorders due to prank calls (14.2\% of the occurrences) [34]. Second, PPE's bulkiness increases blood pressure, heart rate, and the risk of cardiovascular diseases $[35,36]$. It also results in a physiological strain on firefighter [36]. For example, the massive weight causes fall-related injuries as it changes firefighters' center of gravity, flexibility, and mobility [37]. Third, various studies reported that the weight and design of PPE impair firefighters' functional balance and limit their range of motion (ROM) [30]. ROM refers to the range of angular displacement between the longitudinal axes of two adjacent body segments through which these two adjacent segments may move [38].

Injuries related to PPE turnout ensemble: Firefighters face various problems due to the flawed functional design aspect of their turnout ensemble (coat, pants, hood, gloves) in the fire ground. For instance, firefighters sometimes have difficulty accessing cargo pockets while they are on duty, as the placement and design of such pockets are not appropriate [39]. The effect of personal protective turnout coats and pants becomes worse in wildfire activities [40]. In wild firefighting activities, in addition to the weight of different tools and extreme adverse environments, the additional use of the turnout ensemble counterintuitively increases the thermal strain of wildland firefighter [41]. Consequently, it limits firefighters' performance [42].

Properly fitted clothing enhances firefighters' ability to perform work tasks $[43,44]$. Too tight clothing can restrict movement, while too loose clothing can inhibit firefighter's movement and make them more likely to sustain injuries [43]. However, it can be difficult to achieve a proper fit, if garments are not available in size needed. The size and weight of the firefighter garments affect ROM to a great extend [5]. For example, undersized turnout coat and pants affect the hip flexion by reducing the average ROM for about $24 \%$.

Poorly fitting turnout ensembles can restrict firefighters' body movement and comfort. The protective clothing should be moderately loose-fitting, so it contains an appropriate amount of space between the body and the garment. This type of space is the microclimate region [43], which provides a thermal layer to insulate firefighters from thermal hazards $[43,44]$.

In terms of the turnout ensemble design, ergonomic design features such as the tail jacket, which gives participants an impression of lower garment weight burdens, the contoured jacket, which has a higher range of motion than the traditional cut type has, and the contoured knees which help with bending knees [31,32].

Regarding fabrication, the coat and pants have thermal protective features, including a flame- or fire-retardant outer shell, a moisture barrier, and a thermal liner. This encapsulated condition can lead firefighter to heatstroke and cardiovascular malfunction, leading to firefighter deaths on duty [33].

Injuries related to the PPE turnout boots: Structural firefighting boots might directly or indirectly increase firefighters' fatigue and risk of injury through overuse or altering gait cycle and increasing metabolic requirements [43]. For example, researchers found a higher heart rate associated with wearing firefighting boots than wearing sneakers [45]. Besides, multiple studies reported that the poor fit of turnout boot such as looseness and the high outsole is a primary reason for changes in gait and impair safety on the fire ground $[27,46,47]$.

Firefighting turnout boots have a negative impact on firefighters' ROM. For example, boots height may limit firefighters in bending legs [48]. Stiff materials such as ridged outsoles, metal toecaps, and metal shanks are needed for protecting firefighters from the collision. However, these extra attachments can constrain the ankle movement and increase the risk of injury during landing [39]. Additionally, stiff materials, together with poor construction, 
may result in faulty foot function, altered gait, and high flexing resistance $[39,45]$.

Leather boot and rubber boot are the most commonly used two types of boots. Rubber boots can weigh up to $4.4 \mathrm{~kg}$, which adds extra weight to a firefighter's already heavy garment and equipment load [17] and leads to more significant muscular fatigue [49]. In addition, the heavyweight rubber boots cause high metabolic rates and put a considerable burden on the firefighters due to further distance from the wearer's center of gravity [40]. Because of increased metabolic rates, the firefighter wearing heavier rubber boots needs greater oxygen uptake, more significant blood lactic acid, greater mechanical work production, and lower running speed than wearing lightweight leather boots [39].

Researchers' recommendations for improving firefighting boots design include reducing the weight and bulkiness, as well as increasing the flexibility of firefighting boots [39]. Moreover, since firefighters have difficulty taking off boots during quick recovery, two vertical zippers on both sides or a detachable design were proposed for quick doffing and donning [48]. However, few studies of firefighting boot focused on lowering body biomechanics and ergonomic concerns surrounding boot design. As a result, more works is demanded in these areas [45].

Injuries related to the PPE turnout gloves: Turnout gloves protect firefighters from sharp objects, fluids, flame, and heat; thus, firefighters' gloves need to meet specific performance requirements on fit, construction, and materials such as outer shell, moisture barrier, and thermal barrier [50]. In terms of fit, firefighters' gloves need to fit firefighters' multifaceted hand dimensions and shapes [50], as the fit of firefighters' gloves affects essential firefighting operation and the protection of firefighters [50,51]. For example, a tight-fitting glove can restrict finger circulation and increase the risk of burn and frostbite injuries. In contrast, loose-fitting gloves can hinder the accomplishment of finger dexterity and grip tasks [50].

In general, there is a lack of complex and consistent sizing system among manufacturers [27]. The sizing method of firefighter gloves contains several problems. According to NFPA (2012), glove sizing is critical in ensuring firefighter gloves' protection and performance. However, the NFPA standard determines the gloves' size mainly by hand lengths and girths, while the lengths and girths of individual fingers only work as supplemental measurements. More measurements are included in a sizing system, the greater likelihood of achieving a good fit [52]. NFPA's standards on gloves cannot ensure the firefighter hand variations and the excellent fit. Another challenge is the large accommodation range of glove sizes [50]. To minimize this problem, researchers proposed a clusterbased seven-size system of firefighter gloves to include both the overall size of hand and fingers as well as the breadth-to-length contrast instead of a single dimension at a time [50].

Furthermore, gender differences were not considered in glove sizes. Thus, a comprehensive study of the anthropometric data of both male and female firefighters' hands is necessary to improve the sizing and fit of turnout gloves.

Injuries related to the SCBA: SCBA is essential for a firefighter to work in hot and dry environments filled with debris, fine airborne particles, and limited oxygen supply [34]. It is a pressurized bottled supplier of either air, oxygen (02) enriched air or pure 02. It may also induce positive pressure inside the facemask to protect against the inhalation of atmospheric air in the event of a facemask leak [35].

SCBA has a significant impact on firefighter's discomfort and gait due to its heavyweight. The massive weight of an SCBA has a considerable effect on oxygen consumption and metabolic rate $[35,54]$. Besides, SCBA causes gait imbalance by changing the center of mass, which increases the risk of slipping trauma and causes fallrelated injuries [14].

Moreover, firefighters experience restricted head and arm movement, soreness of shoulder, and back pain due to SCBA. The impact is more significant for a firefighter with a relatively shorter frame than a firefighter with a more extended frame. This is because shorter frame firefighters cannot place a SCBA further down on the back to avoid the helmet's back brim from hitting the top portion of the SCBA for ensuring neck mobility [54]. Accordingly, researchers proposed flat-pack SCBA for improving ROM, comfort, and fatigue reduction [27].

Besides, researchers reported issues with the shoulder harness for carrying a SCBA. It interferes with chest motion, affects breathing, and impairs ventilation and gas exchange [28]. Previous researchers and designers propose a design solution to add a soft and wide cushion on the shoulder and hip straps, so there is a better load distribution on the trapezius muscle [35]. Moreover, SCBA straps hinder access to the pocket, which impedes firefighters from reaching tools in the pockets when they need to use [27]. A functional design project covering both the turnout ensemble and SCBA needs to be carried to address this challenge.

\section{Body size and physique variations}

Occupational groups, such as firefighters, have body size or body segment measurements different from general populations $[54,55]$. The U.S. firefighter population's body size and physique are different from those of the general U.S. population $[54,55]$. For example, firefighters' upper-bodies were larger than those of the general U.S. population, suggesting firefighters require specialized sizing systems [54]. Moreover, researchers found that volunteer firefighters have less cardiorespiratory fitness than career firefighters. They have a higher obesity rate and more prehypertension than career firefighters. In addition, wearing full PPE, including SCBA, leads to an exaggerated systolic Blood Pressure and Heart Rate levels to volunteer firefighters than to career firefighters [36]. 
Besides occupations, studies showed that firefighters' hand dimensions are different among gender, race/ethnicity, and age groups [50]. For instance, black firefighters have more elongated hands than other race/ethnicity groups have [50]. Moreover, older firefighters have larger hands than younger firefighters [18]. However, very few studies were conducted on the effect of age on other body dimensions of firefighters.

Age of firefighters: According to a breakdown of the 2015 U.S. fire department profile, half of the firefighters are more than 40 years old [10]. However, more than two-thirds of the firefighters cannot meet the NFPA standard in their fifth decade of life. In addition, $43 \%$ of the female firefighters do not have the same fitness level to meet the aerobic benchmark from age 45 to 54 . On the other hand, firefighters' job demands on physical work capacity remain the same across the age spectrum [55]. According to the 2017 report of firefighter fatalities in the United States, more than half of the firefighters who died of a heart attack were older than forty [24]. Thus, it was suggested that firefighters should increase their physical fitness throughout their careers and do less physically demanding tasks when they are getting old [56].

Female firefighter: Although male and female firefighters work side by side in highly strenuous and risky conditions, there is

Table 1: Articles related to Female Firefighters.

\begin{tabular}{|c|c|c|c|}
\hline Author & Year & Journal/Other Sources & Title of the literature \\
\hline $\begin{array}{l}\text { Watkins ER, Walker A, Mol E, Jahnke S, Richardson } \\
\text { AJ }\end{array}$ & 2019 & Women's Health Issues & Women Firefighters' Health and Well-Being: An International Survey \\
\hline Jahnke SA, Poston, WSC, Jitnarin N, Haddock CK & 2018 & $\begin{array}{l}\text { Maternal and Child } \\
\text { Health Journal }\end{array}$ & Maternal and child health among female firefighters in the U.S. \\
\hline Kirlin LK, Nichols JF, Rusk K, Parker RA, Rauh MJ & 2017 & Occupational Medicine & The effect of age on fitness among female firefighters \\
\hline Park J, Langseth-Schmidt K & 2016 & $\begin{array}{l}\text { International Journal of } \\
\text { Industrial Ergonomics }\end{array}$ & $\begin{array}{l}\text { Anthropometric fit evaluation of firefighters' uniform pants: A sex } \\
\text { comparison. }\end{array}$ \\
\hline Hsiao H, Whitestone J, Kau T, Hildreth B & 2015 & Human factors & $\begin{array}{l}\text { Firefighter hand anthropometry and structural glove sizing: A new } \\
\text { perspective }\end{array}$ \\
\hline Park H, Hahn KHY & 2014 & $\begin{array}{l}\text { Fashion Design, Technol- } \\
\text { ogy, and Education }\end{array}$ & $\begin{array}{l}\text { Perception of firefighters' turnout ensemble and level of satisfaction } \\
\text { by body movement }\end{array}$ \\
\hline $\begin{array}{c}\text { Sinden K, MacDermid J, Buckman S, Davis B, Mat- } \\
\text { thews T, Viola C }\end{array}$ & 2013 & Work & A qualitative study on the experiences of female firefighters \\
\hline $\begin{array}{l}\text { Boorady LM, Barker J, Lin SH, Lee YA, Cho E, Ash- } \\
\text { down SP }\end{array}$ & 2013 & $\begin{array}{c}\text { Journal of Textile and } \\
\text { Apparel, Technology and } \\
\text { Management }\end{array}$ & $\begin{array}{l}\text { Exploration of firefighter bunker gear Part 2: assessing the needs of } \\
\text { the female firefighter }\end{array}$ \\
\hline Hulett DM, Bendick M, Thomas SY, Moccio F & 2008 & $\begin{array}{l}\text { International Associa- } \\
\text { tion of Women in Fire \& } \\
\text { Emergency Services }\end{array}$ & A national report card on women in firefighting \\
\hline
\end{tabular}

Female firefighters are more vulnerable to musculoskeletal injuries due to wearing ill-fitted gear, heavy and bulky equipment, typically designed for males [57]. One of the critical reasons is that, compared to male firefighters, female firefighters, on average, have lower body mass and weaker muscle strength. As a result, female firefighters, when carrying the same weight of fire equipment, experience a more significant physical burden. Besides physical imbalance, this heavier physical burden can directly cause cardiovascular malfunction and heat illness through a sharp limited information published involving female firefighters [5,57] This lack of diversity in the published literature is due to, in part, difficulties accessing the relatively small population of female firefighters [57].

Neither male firefighters nor female firefighters are satisfied with their PPE, however, female firefighters are even less satisfied than their male counterparts $[12,15,16,18,25]$. Female firefighters tend to alter their turnout gear, but typically have difficulty receiving help when dealing with poorly-fitted gear [25]. Also, female firefighters also expressed psychological discomfort concerning the negative impact of wearing ill-fitted uniforms during public presentations [25].

Female specific PPE issues: The gender gap in the firefighting occupation has resulted in institutional barriers for female firefighters [58]. Most firefighting PPE are developed based on male body measurements or via a unisex sizing system, leaving female firefighters to adapt to the ill-fitting sized-down versions of men's gear [18,25,59]. Although women are a minority group in the firefighting occupation, they still deserve the same protective equipment as their male counterparts [18]. The research found that only $25 \%$ of North American female firefighters have access to female-specific PPE, and only $11.5 \%$ were satisfied with it [16]. 
even though the correlation between hand size and the hand/finger breadth-to-length ratio of females is different from that of males $[47,60]$. In addition, about half of female firefighters had a negative experience with boots (46.8\%) and turnout coats/pants (38.9\%).

\section{Conclusion}

The paper is a systematic review of published work on firefighters' duty-related injuries and issues related to the design and size of firefighters' PPE, focusing on female firefighters' specific problems. This review summarized various fire ground injuries associated with the functional design and sizing of firefighting PPE and highlighted literature related to a female firefighter. It also explored research gaps and identified future research opportunities.

\section{Findings}

This review summarized firefighters' injuries related to their PPE and the drawbacks of existing firefighting PPE. It identified dominant barriers to effective protection of firefighter and efficient firefighting performance. The first barrier is the heavy and bulky turnout ensemble, particularly heavy rubber boots and bulky SCBA. The second barrier is the inappropriate sizing system, particularly a lack of female-specific sizing system for female firefighters and improper sizing system of gloves [59]. Articles focusing on male firefighters dominate the research on personal protective equipment, even though the negative impact of PPE on females is more significant than that of males. One of the reasons for the lack of diversity is the lack of access to female firefighters in the firefighting occupation.

This systematic review of the articles provides insights for improving the design, fit, and functionality of future PPE. Improvements such as conducting human factor research, integrating ergonomic features, adopting functional design theory, framework and techniques, and valuing user input in the design and development process of firefighting PPE can all help improve firefighters' safety, performance, and satisfaction [18,30,60-62].

\section{Implications for future research}

Future research opportunities are listed as follows:

- $\quad$ Research and design practices in improving the functional design and sizing systems of firefighting PPE is needed. Particular attention should be placed on (1) reducing the weight and bulkiness of turnout ensemble, particularly boots, and SCBA, and (2) improve the sizing systems of turnout gear, particularly gloves.

- $\quad$ Female firefighters are more vulnerable to injuries than male firefighters are. However, most of the published work regarding the design of PPE and the health of firefighters was based only on male firefighters. More research focusing on improving the design, fit, and function of female firefighters' PPE is demanded.
- Design SCBA to accommodate the variations in firefighters' heights. Currently, the impact of SCBA on a relatively smaller frame firefighter is greater than taller frame firefighters.

- Enhance volunteer firefighters' performance and safety by ensuring cardiorespiratory fitness and designing PPE for this category of firefighters. It is reported that the major percentage of firefighters are volunteer firefighters [10]. However, volunteer firefighters are less cardiorespiratory fitted than career firefighters.

- The design of PPE may follow the firefighters' age spectrum.

\section{Limitation}

Web of science was selected as a database for this review. Although Web of science is an extensive database, including scientific, engineering, social science journals, the database does not include all related publications. Besides, only English publications within the Web of science were reviewed, which may exclude some relevant articles published in other languages. Thus, this study may not have included a few related papers.

\section{Acknowledgement}

This research project was sponsored by USDA National Institute of Food and Agriculture with grant number 1018003.

\section{Conflict of Interest}

Authors declare no conflict of interest.

\section{References}

1. (2020) Statewide fire summary| Cal Fire.

2. Leiva Santos JP, García-Llana H, Pablo V, Liébana M, Kellehear A (2018) Death in the Spanish fire services: A curriculum development study. International Journal of Emergency Services 7(1): 71-82.

3. Sandin P (2009) Firefighting ethics: principlism for burning issues. Ethical Perspectives 16(2): 225-251.

4. Haynes HJG, Molis JL (2017) United States firefighter injuries- 2016, National Fire Protection Association.

5. Kirlin LK, Nichols JF, Rusk K, Parker RA, Rauh MJ (2017) The effect of age on fitness among female firefighters. Occupational Medicine (Oxford, England) 67(7): 528-533.

6. Beaton R, Murphy S, Johnson C, Pike K, Corneil W (1999) Coping responses and posttraumatic stress symptomatology in urban fire service personnel. J Trauma Stress 12(2): 293-308.

7. Jacobsson A, Backteman-Erlanson S, Brulin C, Hörnsten Å (2015) Experiences of critical incidents among female and male firefighters. Int Emerg Nurs 23(2): 100-104.

8. Rossi R (2003) Firefighting and its influence on the body. Ergonomics 46(10): 1017-1033.

9. Smith DL, Fehling PC, Hultquist EM, Lefferts WK, Barr DA, et al. (2012) Firefighter's personal protective equipment and the chronotropic index. Ergonomics 55(10): 1243-1251.

10. Haynes HJ, Stein GP (2017) US fire department profile 2015 National Fire Protection Association, Quincy, MA. 
11. Campbell R (2017) Patterns of female firefighter injuries on the fireground. National Fire Protection Association.

12. Hulett DM, Bendick M, Thomas SY, Moccio F (2008) A national report card on women in firefighting. International Association of Women in Fire \& Emergency Services Madison, WI.

13. Petrucci MN, Horn GP, Rosengren KS, Hsiao-Wecksler ET (2016) Inaccuracy of affordance judgments for firefighters wearing personal protective equipment. Ecological Psychology 28(2): 108-126.

14. Park H, Kim S, Morris K, Moukperian M, Moon Y, et al. (2015) Effect of firefighters' personal protective equipment on gait. Applied Ergonomics 48: 42-48.

15. Park H, Hahn KHY (2014) Perception of firefighters' turnout ensemble and level of satisfaction by body movement. International Journal of Fashion Design Technology and Education 7(2): 85-95.

16. Watkins ER, Walker A, Mol E, Jahnke S, Richardson AJ (2019) Women Firefighters' Health and Well-Being: An International Survey. Women's Health Issues.

17. Chiou SS, Turner N, Zwiener J, Weaver DL, Haskell WE (2012) Effect of boot weight and sole flexibility on gait and physiological responses of firefighters in stepping over obstacles. Human Factors: The Journal of Human Factors and Ergonomics Society 54(3): 373-386.

18. Boorady LM, Barker J, Lin SH, Lee YA, Cho E, et al. (2013) Exploration of firefighter bunker gear Part 2: assessing the needs of the female firefighter. Journal of Textile and Apparel Technology and Management $8(2)$.

19. Kitchenham B (2004) Procedures for performing systematic reviews. Keele University, UK, 33(2004): 1-26.

20. NFPA (2018) NFPA 1582: Standard on comprehensive occupational medical program for fire departments. National Fire Protection Association.

21. Haynes HJG, Molis JL (2017) United States firefighter injuries-2016, National Fire Protection Association.

22. Karter MJ (2012) Patterns of firefighter fireground injuries, National Fire Protection Association, Quincy, MA.

23. Yang J, Teehan D, Farioli A, Baur DM, Smith D, et al. (2013) Sudden cardiac death among firefighters $\leq 45$ years of age in the United States. Am J Cardiol 112(12): 1962-1967.

24. Fahy RF, LeBlanc PR, Molis JL (2018) Firefighter fatalities in the united states-2017, National Fire Protection Association. Fire Analysis and Research Division.

25. Park J, Langseth-Schmidt K (2016) Anthropometric fit evaluation of firefighters' uniform pants: A sex comparison. International Journal of Industrial Ergonomics 56: 1-8.

26. Kahn SA, Patel JH, Lentz CW, Bell, DE (2012) Firefighter burn injuries: Predictable patterns influenced by turnout gear. J Burn Care Res 33(1): 152-156.

27. Park H, Park J, Lin S, Boorady LM (2014) Assessment of firefighters needs for personal protective equipment. Fashion and Textiles 1(1): 8.

28. Kahn SA, Woods J, Sipes JC, Toscano N, Bell DE (2014) Firefighter safety: Rampant unsafe practices as documented in mainstream media. J Burn Care Res 35(5): 426-430.

29. Guidotti TL (1992) Human factors in firefighting: ergonomiccardiopulmonary-, and psychogenic stress-related issues. Int Arch Occup Environ Health 64(1): 1-12

30. Ciesielska-Wróbel I, DenHartog E, Barker R (2017) Measuring the effects of structural turnout suits on firefighter range of motion and comfort. Ergonomics 60(7): 997-1007.

31. Fent KW, Alexander B, Roberts J, Robertson S, Toennis C, et al. (2017) Contamination of firefighter personal protective equipment and skin and the effectiveness of decontamination procedures. J Occup Environ Hyg 14(10): 801-814.
32. Park E, Lee YJ, Lee SW, Bang CH, Lee G, et al. (2016) Changes of oxidative/ antioxidative parameters and DNA damage in firefighters wearing personal protective equipment during treadmill walking training. J Phys Ther Sci 28(11): 3173-3177.

33. Soteriades E, Smith D, Tsismenakis A, Baur D, Kales S (2011) Cardiovascular disease in US firefighters: A systematic review. Cardiol Rev 19(4): 202-215.

34. Contrera-Moreno L, de Andrade SMO, Motta-Castro ARC, Pinto AMAC Salas FRP, et al. (2012) Analysis of working conditions focusing on biological risk: firefighters in Campo Grande, MS, Brazil. Work 41(Suppl 1): 5468-5470

35. Bakri I, Lee J, Nakao K, Wakabayashi H, Tochihara Y (2012) Effects of firefighters' self-contained breathing apparatus' weight and its harness design on the physiological and subjective responses. Ergonomics 55(7): 782-791.

36. Feairheller DL (2015) Blood pressure and heart rate responses in volunteer firefighters while wearing personal protective equipment. Blood Press Monit 20(4):194-198.

37. Park K, Rosengren KS, Horn GP, Smith DL, Hsiao-Wecksler ET (2011) Assessing gait changes in firefighters due to fatigue and protective clothing. Safety science 49(5): 719-726.

38. Kreighbaum E, Barthels KM (1996) Biomechanics: A qualitative approach for studying human movement Allyn and Bacon Boston, MA USA.

39. Park H, Trejo H, Miles M, Bauer A, Kim S, et al. (2015) Impact of firefighter gear on lower body range of motion. International Journal of Clothing Science \& Technology 27(2): 315-334.

40. Taylor NA, Lewis MC, Notley SR, Peoples GE (2011) The oxygen cost of wearing firefighters' personal protective equipment: Ralph was right. The ICEE 2011 XIV International Conference on Environmental Ergonomics. Nafplio, Greece.

41. Bruce-Low SS, Cotterrell D, Jones GE (2007) Effect of wearing personal protective clothing and self-contained breathing apparatus on heart rate, temperature and oxygen consumption during stepping exercise and live fire training exercises. Ergonomics 50(1): 80-98.

42. Song G, Mandal S, Rossi R (2017) Thermal protective clothing for firefighters. Woodhead Publishing, UK.

43. Stull JO, Stull GG (2013) PPE size and fit: A safety issue.

44. Carballo-Leyenda B, Villa JG, López-Satué J, Rodríguez-Marroyo JA (2017) Impact of different personal protective clothing on wildland firefighters' physiological strain. Front Physiol 8: 618.

45. Spratford W, Vu V, Ball N, Walker A. (2017) Protective firefighting boots and their impact on the lower body and injury: A narrative review. Occupational Ergonomics 13(3-4): 147-155.

46. Derella CC, Aichele KR, Oakman JE, Cromwell CM, Hill JA, et al. (2017) Heart Rate and Blood Pressure Responses to Gear Weight Under a Controlled Workload. J Occup Environ Med 59(4): e20-e23.

47. Goonetilleke RS (2013) The science of footwear. Boca Raton, Fla.: CRC Press, Taylor \& Francis, USA.

48. Lee J, Kim S, Jang Y, Baek Y, Park J (2014) Component contribution of personal protective equipment to the alleviation of physiological strain in firefighters during work and recovery. Ergonomics 57(7): 1068-1077.

49. Garner JC, Wade C, Garten R, Chander H, Acevedo E (2013) Corrigendum to "The influence of firefighter boot type on balance". International Journal of Industrial Ergonomics 43(3): 246-248.

50. Hsiao H, Whitestone J, Kau T, Hildreth B (2015) Firefighter hand anthropometry and structural glove sizing: A new perspective. Human Factors 57(8): 1359-1377.

51. McKenna M (2009) Firefighting gloves: Finding the right fit.

52. Hsiao H, Whitestone J, Kau T, Whisler R, Routley JG, et al. (2014) Sizing firefighters: Method and implications. Hum Factors 56(5): 873-910. 
53. Hsiao H, Long D, Snyder K (2002) Anthropometric differences among occupational groups. Ergonomics 45(2): 136-152.

54. Lusa S, Louhevaara V, Kinnunen K (1994) Are the job demands on physical work capacity equal for young and aging firefighters? J Occup Med 36(1): 70-74.

55. Dobson M, Choi B, Schnall PL, Wigger E, Garcia-Rivas J, et al. (2013) Exploring occupational and health behavioral causes of firefighter obesity: A qualitative study. Am J Ind Med 56(7): 776-790.

56. Jahnke SA, Poston WSC, Jitnarin N, Haddock CK (2018) Maternal and child health among female firefighters in the U.S. Matern Child Health J 22(6):922-931.

57. Sinden K, MacDermid J, Buckman S, Davis B, Matthews T, et al. (2013) A qualitative study on the experiences of female firefighters. Work 45(1): 97-105.
58. International Association of Women in Fire and Emergency Services (2017) FAQs on Women in the Fire \&amp; Emergency Services.

59. Federal Emergency Management Agency (2019) Emerging Health and Safety Issues Among Women in the Fire Service.

60. Poston WS, Haddock C, Jahnke S, Jitnarin N, Tuley B, et al. (2011) The prevalence of overweight, obesity, and substandard fitness in a population-based firefighter cohort. J Occup Environ Med 53(3): 266273.

61. Coca A, Roberge R, Shepherd A, Powell JB, Stull JO, et al. (2008) Ergonomic comparison of a chem/bio prototype firefighter ensemble and a standard ensemble. Eur J Appl Physiol 104(2): 351-359.

62. Luo C, Jin J (2012) Design feature analysis and pilot ergonomic evaluation for protective fire gear. Procedia engineering 43: 374-378. 